Rev. Elev. Méd. Vét. Poys trop., 1968, 21, 2 (165-179)

\title{
Utilisation en Afrique centrale d'un vaccin aviaire polyvalent *
}

\author{
par A. PROVOST ef C. BORREDON \\ (I. E. M. V. T., Laboratoire de Recherches Vétérinaires de Forcha, \\ Fort-Lamy, Tchad)
}

\begin{abstract}
RÉSUMÉ
L'éventail relatıvement restreint des épizooties frappant les volailles autochtones d'Afrique centrale, l'absence apparenle d'infection leucosique chez ces oiseaux, la raréfaction d'une main-d'œuvre qualifiée imposant le minimum d'interventions vaccinales ef la nécessité de l'immunisation à large spectre des volailles d'importation, ont conduit à l'adoption d'un vaccin vivant iyophilisé mixte contre la maladie de Newcastle, la variole aviaure et la iyphose, inoculable en un seul temps dès la troisième semaine de la vie. Les deux premiers composants de ce vaccin sont obtenus sur cellules bovines en culture afin de ne pas transmettre d'infections aviaires; le troisième falt appel à $S$. gallinarum souche $9 R$. Après 5 années d'expérience, les résultats enregistrés sur le terrain sont très satisfalsants.
\end{abstract}

Le vaccin aviaire polyvalent qui sera décrit dans les lignes suivantes n'a pas la prétention d'être une panacée pour l'aviculture mondıale. II est présenté comme une solution apportée à quelques problèmes de pathologie infectieuse des volailles domestıques spéciaux à l'Afrique centrale (**). Il est vraisemblablement perfectible. Comme néanmoins il donne des résultats satısfaisants depuis 5 ans qu'il est employé, nous avons cru bon de présenter quelques commentaires sur la genèse de sa conception et sur des points particuliers de sa production, de son contrôle et de son utilisation.

* Communication présentée au 18 congrès mondial vétérinaire, Paris 17-22-juillet 1967.

(**) La dénomination Afrique centrale s'entend de l'aire d'action du laboratoire de Farcha qui couvre les Républiques du Tchad, Centrafricaine, du Gabon, du Congo et de la République fédérale du Cameroun.

\section{1. - INTRODUCTION}

\section{LA NÉCESSITÉ D'UNE IMMUNISATION POLYVALENTE.}

1. Etat actuel de l'aviculture en Afrique centrale.

II n'est pas dans ce propos d'entreprendre une étude zoofechnique ou économique sur les mérites respectifs pour l'Afrique centrale de l'élevage avicole en parquets ou de l'élevàge familıal. Tout au plus donnera-t-on un très bref aperçu des types d'élevage avicole qu'on $y$ rencontre.

De loin le plus nombreux est l'élevage traditionnel fomilial. L'effectif est difficile à évaluer; au Tchad, on peut légitimement penser qu'il doit $y$ avoir 4 millions de poulets, 900.000 en R. C. A., 800.000 au Congo, 200.000 au Gabon, 1.500 .000 dans le Nord-Cameroun. Sans être l'objet de soin 
spéciaux (ce que l'on peut déplorer car les pertes sont lourdes), cet élevage se rencontre partout, autour des cases, depuis les villages de la forêt jusqu'à ceux du sahel tchadien. Les races sont incertaınes mals paraissent se rattacher à un type «coureur» de petite taille que RECEVEUR appelle «poulet centre-africain».

L'alimentation est simplifiée : ce sont les débris de vanage et de pilage du mil, du mais ou du manioc, les jours fastes quelques reliefs de cuisıne. Le complément alimentaire est recherché par les volailles, vivant à l'état d'entière liberté, dans la brousse avoisinant le village où elies trouvent des graminées sauvages ef des proies vivantes (batraciens, lézards, gastropodes, insectes).

Les œufs, quand on les trouve, ne sont pas consommés; ils sont laissés à la pondeuse qui, une fois sa ponte terminée, les couve. Les poules sont bonnes mères, comme beaucoup d'oiseaux scuvages, ce qui est heureux car les poussins ne sont l'objet d'autres soins que ceux qui consistent à les enfermer le soir pour les mettre à l'abrı des petıts carnassiers (6). La chair elle-même n'est pas l'objet de consommation courante; c'est un luxe réservé à quelque cérémonie et à une catégorie sociale aisée; plus souvent, le poulet est un présent offert à un hôte de passage.

Cet élevage familıal traditionnel reste ainsi, pour l'instant, un authentique produit de cuelllette. II ne faut pas pour cutant en sous-estimer la valeur, car si modeste soit-il, il est une source de protéines animales obtenues à peu de frais et sans travail. Il est traditionnel d'admettre que la rusticité de ces volailles est d̀ toute épreuve. C'est du moins l'impression que fournit l'observation superficielle des poules vivant autour des cases dans les conditions qui viennent d'être rapportées. Toutefois, si l'on comptabilıse la production d'œufs, on s'aperçoit que le taux d'éclosion varie de 30 à 70 p. 100 et qu'à peine $1 / 3$ des poussıns parviennent à l'âge adulte. Des carences alimentaires interviennent évidemment, mais nous verrons qu'existent aussi des problèmes de pathologie auxquels il serast facile de remédier.

L'élevage amélioré est d'introduction très récente. Les effectifs sont encore modestes: moins de 10.000 sujets au Tchad et autant d'importation annuelle de poussins d'un jour ; 19.000 en R. C. A. avec 100.000 importations annuelles de poussins : 4.000 sujets au Gabon; une quarantaine de mille au Congo, mais plus de 3 millions dans le Sud-Cameroun.

Les races sont diverses, d'origine européenne et américaine. La préférence va aux croisements spécialisés pour la ponte ou la charr. On peut déplorer que des importations anarchiques ou non contrôlées aient introduit des gènes morbides (malformations des pattes) ou des germes infectieux (pullorose).

La nourriture est soit importée d'Europe, soit produite sur place dans de petites exploitations avec les céréales locales (mil, mas, riz, manioc), des tourteaux d'arachide, des farines de sang et de viandes, sous-produits d'abattoir. Les compléments mınéraux et vitaminiques sont importés.

Mis à part le Sud-Cameroun, la production d'cufs dont le prix oscille entre 25 et 45 francs CFA l'unité, ne trouve acheteur que dans la population européenne ou la bourgeoisie africaine. Il en est pour l'instant de même des poulets de chair.

L'impression générale est que l'élevage des races améliorées est facile. II ne se pose pas de très gros problèmes de pathologie; les erreurs alımentaires sont vite corrigées car le forçage en vue d'une rentabilité accrue n'a pas la même ampleur qu'en Europe.

Il est un point sur lequel Il paraît bon d'ınsister et qui explique ce fait. II n'existe aucune intrication entre les deux modes d'élevage : l'élevage amélioré est citadın, se fait en vase clos; l'élevage traditionnel est essentiellement rural. Sa commercialısation ne se falt que sur les marchés, en vue de la consommation immédiate. Aussi n'y a-t-il que peu de passage de la pathologie de l'un à l'autre.

Depuis plusieurs années sant réalisées des introductions de volailles de races améliorées dans les villages de brousse. L'absorption se fait immédiatement; dans les mois suivants on ne retrouve plus les oiseaux introduits mais on note depuis quelques années une tendance à l'augmentation du format des poulets présentés sur les marchés locaux comme du poids des cufs.

Canards et pigeons ne seront mentionnés que pour mémoire.

\section{Inventaire de pathologie avicole.}

La pathologie des oisecux domestiques d'Afrique centrale est relativement pauvre à telle enseigne qu'un grand accouveur français estime 
qu'il serait, de ce fait, plus rentable de produire des poussins en Afrique qu'en Europe.

En élevage familial, elle ne possède que deux composantes, l'une infectieuse, l'autre parasitaire. Le côté alımentaire n'a pas lıeu d'être évoqué puisque l'une des caractéristiques de cet élevage est justement de ne pas s'en préoccuper. La simple observation montre d'ailleurs que poules et canards parviennent à assurer leur croissance et leur reproduction avec la noursiture qu'ils glanent çà et là.

En élevage amélioré et industriel, les erreurs alimentaires s'observent de temps à autre. Ce sont :

des hypovitaminoses $B$ entraînées par un excès de poisson cru dont l'intestin contient des antivitamınes B,

des hypovitaminoses $E$ se traduisant par le syndrome d'encéphalomalacie de nutrition sur les poussins âgés de 3 semaines d̀ un mois,

des hypocalcémies (œufs à coquille fragile ou sans coquille),

des hyperprotidoses, les propriétaires croyant bien faire en ajoutant des protéines (viande, poisson) aux aliments dits «complets» achetés dans le commerce. Ces erreurs sont aisément corrigées. Reste la pathologie infectieuse ef parasitare, touchant tous les types d'élevage.

La maladie de Newcastle a été diagnostiquée au Congo dès 1941 (19) puis de nouveau en 1949 (25). De là elle aurait gagné l'Oubangui-Chari (actuellement R. C. A.), puis le Tchad en 1954. L'opinion commune veut que la maladie soit répandue, ce dont font écho les rapports de l'O. I. E. et de la F. A. O. car on a tendance d̀ appeler «peste aviaire » toute mortalité des poules. II est bon de faire remarquer que le virus n'a été isolé et authentifié que deux fois par le laboratore de Farcha : une fois en décembre 1959, dans de petits élevages familiaux de Fort-Lamy, la mortalité des poules étant alors contemporaine de celle des mange-mil (Quelea quelea); à la même époque, le virus était isolé au Congo (9). L'autre occasion s'est présentée en novembre 1962 dans quelques élevages familiaux de la même ville du Tchad. A notre connaissance en aucune autre circonstance le virus de Newcastle n'a été authentifié. II n'existe que des rapports d'autopsie, sans tentative d'isolement du virus, lassant penser que la maladie évolue peut-être à bas bruit en R. C. A. On a signalé en Nigeria et au Sou- dan d'importantes mortalités dues à cette virose $(16,17)$.

It est donc possible mais non certain que la maladie de Newcastle existe à l'état enzootique ; très objectivement, elle ne paraît pas occasionner de grosses pertes dans les états d'Afrique centrale. Son incidence économique reste à démontrer. Des sondages sérologiques réclisés sur des sérums de poules locales tchadiennes non vaccinées et sur des sérums d'orseaux sauvages (oie d'Egypte, oie caronculée) montrent la présence d'anticorps inhıbant l'hémagglutination dans les sérums des anatidés sauvages, ce qui laısse supposer que la maladie existe au moins sous forme asymptomatique dans ces espèces et qu'elle peuł représenter un danger pour les volaılles (13). Une enquête réalisée au Congo indique que 7 p. 100 des poules des villages possèdent des anticorps naturels à un taux significatif (9).

On est donc avec la maladie de Newcastle dans une situation où on peut penser que la virose existe mais en quelque sorte sous une forme occulte dont on peut toujours craindre un réveil (*).

Lo variole aviaire est, par contre, très répandue. Témoins en sont les cicatrices rencontrées sur les crêtes et les barbıllons de pratiquement toutes les poules. Le mode de contagion médiat paraît ètre plus important que la contagion directe, les moustiques jouant le rôle de lancettes infectées de virus. Toutes les formes cliniques se rencontrent, les plus graves étant la stomatite et la sinusite qu'aggrave au Tchad leur apparition en saison fraîche et sèche, entraînant la dessiccation des fausses membranes. Volalles autochtones et améliorées paient tribut à la maladie ; chez ces dernières, la ponte est gravement perturbée.

L'encéphalomyélite aviaire, la monocytose aviare ont été signalées chacune une fois dans des élevages européens.

Les leucoses posent un problème particulier.

(*) Ces lignes ont été écrıtes en avrıl 1967. En janvier 1968 est apparue dans la région lamyfortaine une flambée de maladie de Newcastle, ne laissant que des cadavres dans les poulaillers nan vaccinés et dans les élevages famıliaux traditionnels. On mesure en ces circonstances combien paraît fondée la proposition émıse plus loin de la nécessité de la vaccınation anti-Newcastle bien avant que n'existe l'épizootie. 
Elles sont fréquentes sur les races importées, certaines souches paraissant être plus sensibles que d'autres. Mais Il est intéressant de sıgnaler qu'aucune forme de leucose (sanguine ou viscérale) ni de neurolymphomatose n'a jamais été rencontrée chez les poules locales sur les milliers d'autopsies pratiquées. Il ne paraît pas s'agir d'un état de résistance particulier, comme le montre leur réceptivité à l'inoculation du virus du sarcome de ROUS, mais de leur non-infection par les virus leucosiques. Une expérience du laboratoire de Farcha (24) a prouvé qu'un échantillon de poules locales n'excrétait pas de virus RIF dans leurs ceufs et n'hébergeait pas d'anticorps antivirus de ROUS. II est malheureusement difficlle d'étendre ces résultats à toute l'Afrique centrale en raison de la complexité et du temps requis pour les épreuves virologiques mises en cuvre. incidemment on remarquera que des oiseaux domestiques et sauvages d'Afrique Orientale possèdent des anticorps antivirus de ROUS (20). II s'agıt donc peut-être là d'un état de fait heureux pour l'Afrique centrale pour autant que l'absence du virus RIF soit un authentique témoin de l'absence de virus leucosiques, ce dont doutent certains auteurs (29) ; néanmoins il paraît bon de remarquer que les pathologistes aviaires ignorent les leucoses sur les volailles autochtones d'Afrique occidentale (17).

Le choléra oviaire a été autrefois signalé sous sa forme chronique au Congo (26). II existerait encore avec une incidence sporadique au Gabon mais la pasteurelle n'a jamais été isolée ni identifiée.

Les infections solmonelliques sont extrêmement fréquentes, tout particulièrement celles causées par Solmonella gallinarum-pullorum. La pullorose est plus rare que la typhose, cette dernière se manifestant chez les pondeuses. La mortalıté est constante, échelonnée dans le temps. Poules locales et races importées sont également touchées. II ne paraît pas autrement exagéré de dire que les poules aduites, ayant survécu aux autres causes morbides, auront toutes chances de mourir avant l'âge de 2 ans de typhose ; il est en tout cas patent de ne voir en Afrique centrale que des volailles jeunes. Sur les poules locales vues à l'autopsie, cette maladie représente plus de la moitié des cas. A côté de la typhose, d'autres infections à entérobactéries peuvent toucher les volailles : différentes Solmonella (21), plusieurs sérotypes de colıbacilles et, récemment identifié, Edwardsiella tarda sont isolés (27). Leur incidence n'est que sporadique; il s'agit surtout d'infections d'élevage mal tenus.

La spirochétose est un problème préoccupant dans la partie sahélo-soudanaise de I'Afrique centrale (Tchad, région de Birao en R. C. A., NordCameroun). Elle paraît ne pas exister en altitude (Adamaova) ni sous les climats équatoriaux, ceci très vraisemblablement en rapport avec l'absence de l'un de ses vecteurs, Argas persicus, de ces. régions. Ailleurs elle est très fréquente. L'observation montre que tôt ou tard poules locales ou importées font un accès de spirochétose clinique. Morbidité et mortalité sont importantes, surtout en début de saison des pluies, mals l'accès n'est pas toujours mortel si n'existent pas d'autres causes morbides concomitantes (typhose latente, infestations vermineuses); nécnmoins il ébranle profondément le comportement des volailles, entraîne des retards de croissance, stoppe la ponte, détermine des lésions hépotıques (dégénérescence graisseuse) qui laissent les oiseaux sans défense vis-à-vis des infections ultérieures. singulièrement de la typhose. L'association pathogène spirochétose-aegyptianellose ou spirochétose-variole est responsable d'hécatombes dans les poulaillers. La prophylaxie sanitaire de la maladie est Illusoire étant donné la pullulation des moustiques vecteurs. Le traitement à la pénicillıne réussit bıen quand il est financièrement accessible par les propriétaires ; il reste toujours des lésions hépatiques au pronostic redoutable.

Les maladies respiratoires dans leur ensemble ne paraissent pas constituer un problème. Mycoplasma gallisepticurn a été isolé à plusieurs reprises de cas de sinusites de volailles locales et de lésions des sacs aériens de poules importées ; la maladie respiratoire chronique $n$ 'est pourtant pas reconnue comme une entité clinique. La bronchite infectieuse, la laryngotrachéite sont inconnues. Une sinusite d̀ Hemophilus peut occasionnellement sévir en saison fraîche au Tchad et compliquer les cas d'épithélioma variolique; elle est rare. Contrastant avec ce tableau d'ensemble rassurant, on signale pourtant depuis quelques mois à Bangu des maladies respiratoires d'étiologie imprécisée.

Lo tuberculose existe : c'est une maladie rare, apanage de quelques volailles autochtones en certaines régions (Mayo-Kebbı au Tchad). 
Les parasitoses variées ne seront pas envisagées ici. Elles ont fait l'objet d'enquêtes depuis plusieurs années et d'expériences dans le choix d'anthelminthiques efficaces et polyvalents (13, 24). Les infestations vermineuses sont redoutables dans tous les élevages. Ascaridiose et taeniasis sont extraordinairement fréquents et, quoi qu'on en puisse penser, mal supportés par les oiseaux. lis diminuent leur résistance vis-à-vis des autres causes morbides.

Les coccidioses forment un fond pathologique sous les climats équatorıaux à humidité constante pour la volaille d'importation; les poules locales sont porteuses d'ookystes mais moins cliniquement touchées. La maladie est plus rare sous le climat sahélien sauf en saison des pluies.

\section{Nécessifé d'un vaccin associé.}

Du bref inventaire de pathologle infectieuse avıaire qui vient d'être dressé se dégagent quelques points saillants.

La maladie de Newcastle paraît ne pas exister ou est très localisée; l'ensemble de la population aviaire domestique est donc sensible et exposé à une incursion du virus (ce que montrent d'alleurs les inoculations expérimentales réalisées au laboratoire).

D'importance égale paraissent être la varıole, la typhose ef la spirochétose.

Les autres infections ne sont que mineures.

Il est, en ces circonstances, nécessaire de songer à une prophylaxie médicale des quatre grandes maladies ci-dessus évoquées. Dans cette optique, le laboratoire de Farcha depuis 1955 a produit plusieurs vaccins, contre la maladie de Newcastle (souche BEAUDETTE), la variole (souche virulente d'ovoculture) et la typhose (germes inactivés par le formol). Quant à la spirachétose il a récemment été possible de mettre un vaccin au point.

Les vaccins monovalents ont toutefors le désavantage de requérır plusieurs interventions ce qui, dans des pays où la main-d'œuvre qualifiée est insuffisante, pose des problèmes. On remarquera au passage que vaccins contre la variole et la typhose, d'emploi quasi obligatoire, demandant nécessairement une manipulation des oiseaux, on pouvait songer en profiter pour immuniser en même temps contre la maladie de Newcastle. L'emploi de vaccins buvables contre cette maladie nous paraît en effet être d̀ proscrire en Afrique tropicale, tout spécialement dans les climats sahélo-soudanais, en raison de l'inactivation possible due aux conditions météorologiques et aux fréquentes impuretés des eaux rencontrées ( $\mathrm{pH}$ trop acide ou trop basique).

C'est pourquoi a été tentée l'association de plusieurs immunigènes dans un vaccin plurivalent à usage aviaire ; il comporte actuellement les antigènes : virus de Newcastle, de la variole et S. gallinarum. II est dans l'esprit d'y adjoindre un antıgène contre la spirochétose quand celul-ci sera au point. II fut décidé que ce vaccin serait injectable, mettant à profit pour le virus variolique les normes d'immunisation intramusculaire définies par BASSET (4).

Ce vaccin n'est pas spécialement révolutionnaire puisqu'il reprend l'idée de vaccins de certaines maisons de commerce $\left({ }^{*}\right)$. Son originalité tient dans le choix des souches et dans son mode de préparation qui en font un produit adapté à l'Afrique centrale.

\section{II. - PRODUCTION ET CONTRÔLEE DU VACCIN POLYVALENT}

\section{Principes directeurs - choix des souches.}

De la nécessıté d'une intervention unıque pour vacciner les volailles, oblıgatıon résultant de la rareté de la main-d'œuvre pouvant pratiquer I'opération, découle le choix de vaccins à germes vivants plutôt qu'à immunigènes inactivés, les premiers étant réputés fournir des périodes de protection plus longues que les autres. Cas commun pour les antigènes Newcastle et variole pour lesquels abondent les souches vaccinales, le choix de l'antigène S. gallinarum pouvait s'avérer plus délicat.

Il fallalt tenir compte d'autres facteurs dont le plus important paraissait être l'apparente absence de virus des leucoses chez la volaille locale. Or pour certaines raisons (Impossibilité d'avoir de grosses quantités d'œufs avec les poules locales, faible volume des œufs, possibilité de contamination salmonellique), le laboratoire est dans la nécessité d'importer des œufs d'Europe pour produire ses vaccins d'ovoculture (dont un

(*) Avimix de l'Institut Mérieux. 
vaccin antipéripneumonique). Ce faisant, il est possible qu'il importe en même temps le virus de Newcastle, des mycoplasmes ou d'autres agents pathogènes transmis par les œufs, dont surtout des virus leucosiques qui pourraient se retrouver dans ses vaccins d'ovoculture comme I'a montré BURMESTER (8). Bien qu'il soit admis que la réceptivité aux virus des leucoses ne soit entière que durant les tous premiers jours de la vie de l'oiseau, il a été montré dans le cas des poules autochtones du Tchad que les adultes étaient réceptıfs (au moins au virus de ROUS). Gardant également à l'esprit que les leucoses aviaires sont authentiquement contagieuses ( 7 . 10), Il ne pouvait paraître logique que le laboratoire de Farcha produise un vaccin aviaure destiné à une grande diffusion en Afrique centrale et pouvant entraîner des risques de dispersion de maladies qui n'y sont apparemment pas présentes. En conséquence, le choix des souches vaccinales s'est orienté vers des souches capables d'être cultivées en cellules hétérologues.

Pour le virus de Newcastle, plusieurs souches s'offraient. Le choix final s'est orienté vers la souche BANKOWSKI $(2,3)$ qui jouit de qualités immunigènes solides. Cultivable en cellules rénales de porc ou de veau, la technologie de sa production avait déjà été étudiée par l'un de nous (23). On pouvait craindre qu'elle soit trop pathogène, ce qui a été vérifié selon les normes classiquement admises (1) : dans nos mains, son «indice de neurovirulence» a été trouvé de 0,54 et «l'index de pouvoir pathogène par voie intraveineuse » égal à zéro; elle tue l'embryon de poulet en 96 heures environ. Elle se situe donc entre les souches lentogènes et mésogènes. Dans ces conditions il paraissait loisible de pouvoir I'utiliser en Afrique centrale parce qu'offrant les avantages requis d'innocuité satisfaisante, de qualités vaccinales puissantes et la faculté d'être produite sur cellules bovines dont disposait le laboratoire (*).

Le choix du virus variolique s'avérait plus délicat. Après plusieurs esscis plus ou moins heureux, le laboratoire s'était arrêté au choix de la souche BEAUDETTE de virus variolique aviaire pour produire son vaccin antivariolique d'ovoculture.

(*) Nous devons à l'amabilité du Professeur BANKOWSKI l'envoi de la souche et l'autorisation de l'incorporer dans le vaccin polyvalent.
Cette souche de bon pouvoir immunigène $(19,22)$ avait par ailleurs la qualité d'avoir un spectre antigénıque étendu, ce qui n'est pas avec toutes. les souches vaccinales de variole aviaire. La nécessité évoquée ci-dessus d'utiliser des cellules hétérologues devait faire chercher une souche variolique cultivable sur de telles cellules. II n'en existe pas à notre connaissance. Dans ces conditions fut tentée l'adaptation de la souche BEAUDETTE à la culture en cellules de rein d'embryon de veau. Cette adaptation s'est révélée être particulièrement aisée (24). Après 2 passages, la souche s'est montrée régulièrement cytopathogène pour ces cellules, entraînant une destruction d'abord focalisée du tapis sous forme de plages circulaires acellulaires, s'étendant ensuite à tout le tapis de cellules par coalescence après une adaptation au cours de laquelle il croît régulièrement. Le titre en virus des milieux, au 6 e jour de culture, dépasse $10^{7}$ dose infectante 50 par ml pour la membrane chorioallantoïdienne de l'embryon de poulet. Pour les deux virus de Newcastle et variolıque, des «banques » ont été constituées lyophilisées et conservées d̀ $-200 \mathrm{C}$; elles servent à assurer la production d'une année.

L'argumentation qui vient d'être présentée quant au choix de souches vaccinales cultivables. en cellules hétérologues vaut surtout pour la production d'un vaccin destiné aux volailles locales. Il a moins d'intérêt pour la volaille importée, dont on peut à bon droit penser que tôt ou tard elle aura un contact avec les virus leucosiques. Nous nous sommes aperçus, après deux années de vulgarisation du vaccin polyvalent, que ce dernier n'étalt utilisé que dans les élevages améliorés. Coîncidant avec des difficultés temporaires de production de cultures cellulaires, la connaissance de ce fait a entraîné la décision de fabriquer quelques lots avec un immunigène varıolique d'ovoculture utilisant la souche BEAUDETTE, conservant toutefois le composant Newcastle de cultures cellulaires qui allie les avantages d'une absence de tropisme respiratorre, de non-disséminatıon du virus par les vaccinés et d'une immunisation de longue durée.

L'immunıgène contre la typhose aviarre (culture formolée), que produisalt le laboratoire depuis plusieurs années, ne donnant qu'une satisfaction. modérée, on avait songé farre appel au vaccin vivant Salmonella gallinarum souche $9 \mathrm{R}$ de WILLIAMS SMITH (28). Cette souche $9 \mathrm{R}$ est 
réputée posséder un bon pouvoir antigénique (14) et être d'une innocuité satisfaisante (12). Sa culture s'est avérée être facile et sa lyophilisation aisée.

Les liquides de culture cellulaire des antigènes NEWCASTLE et variole du futur vaccin contenant au moins deux antibiotıques (pénicilline et streptomycine), il fallait savoir quel était le comportement de la souche $9 R$ vis-à-vis de ces antibiotiques. Elle s'est avérée être complètement résistante à la pénicilline, modérément sensıble à la streptomycine. Une sélection d'un mutant streptomycino-résistant a donc été réclisée très simplement par culture en bouillon tryptose de la souche en présence de dilutions de streptomycine de $0,001 \mu \mathrm{g}$ à $100 \mathrm{mg} / \mathrm{ml}$; repartant de ces derniers tubes où il y avait eu une culture, on a repiqué dans des tubes contenant la même concentration d'antibiotique; la culture fut florissante (24). Au mutant streptomycino-résistant ainsi produit fut donné le sigle de 9 R-S R.

Une banque lyophilisée en 1964 sert à la production depuis lors. La production des différents constituants du vaccin sera maintenant décrite temps par temps puis sera brossée la synchronisation des opérations.

\section{Antigène Maladie de Newcastle.}

La production de cet antigène se fait sur cellules de rein d'embryon de veau en culture. Les cellules de première explantation sont d'abord cultivées en boîte de Roux dans $100 \mathrm{ml}$ de milieu à l'hydrolysat de lactalbumıne à 10 p. 100 de sérum de veau, contenant 4 antibiotiques et un fongistatique; au bout de cinq jours, elles sont décollées au versène ef repiquées dans des flacons à plosma de 1 litre, chaque flacon contenant $200 \mathrm{ml}$ du même milieu à l'hydrolysat de lactalbumine à 10 p. 100 de sérum de veau. Ces flacons sont placés dans des alvéoles sifués sur une roue qui tourne à la vitesse de 7 tours à l'heure dans une chambre étuve à $37^{\circ}$. De cette façon, il est obtenu en six jours une couche monocellulaire parfaitement uniforme sur la parol de chaque flacon.

Les flacons sont alors vidés du milieu de croissance et chacun reçoit 2 millilitres d'une suspension de la souche BANKOWSKI, cet inoculum étant réalisé en eau distillée à partır d'un flacon de la banque de virus lyophilisé.
Le contact cellule-virus est maintenu pendant deux heures, les flacons étant replacés dans leurs alvéoles sur ia rove. Ensulte chaque flacon reçoit 100 millilitres de milıeu à l'hydrolysat de lactalbumine à 10 p. 100 de sérum de veau (avec 2 antibiotiques seulement : pénicilline et streptomycine).

Les flacons tournant sont laissés à l'étuve pendant 72 heures, temps au bout duquel on procède à la récolte. En effet, bien qu'alors l'effet cytopathique soit très discret, les tıtrages de virus réalisés en œuf embryonné indiquent que c'est à ce moment que les liquides de cultures sont les plus riches en virus (entre $10^{3}$ et $10^{8} \mathrm{DIE}_{50}$ ipar $\mathrm{ml}$ ).

Les liquides sont collectés dans un ballon de 2 litres maintenu dans la glace fondante. Les. cellules sont décollées des parors des flacons à I'aide de billes de verre, broyées finement dans un broyeur conique en verre rodé puis mélangées au liquide de culture dans le ballon de 2 litres.

Ces opérations étant terminées, le ballon contenant les cellules broyées et le milieu de culture est placé au réfrigérateur à $+4^{\circ} \mathrm{C}$.

\section{Antigène variole aviaire.}

La production de cet antigène se fait sur des cultures cellulares identiques aux précédentes. L'infection cellulaire est réalisée dans des conditions similaires avec le virus lyophilisé de la banque.

La récolte a lieu avec des modalités semblables à celles de l'antigène Newcastle le be jour après l'infection cellulaire. Le ballon de récolte est placé à $+4^{\circ} \mathrm{C}$.

Pour les lots de vaccin contenant l'antigène variolique d'ovoculture, on a suivi la technique générale de production de JOHNSON et VAUGHAN (18) où l'inoculation des cufs se fait par le bout pointu. Les membranes chorioallantoidiennes sont recueillies dans un flacon placé dans de la glace fondante, pesées puis broyées et homogénéisées dans un «mixeur» de type domestique. Elles sont diluées à parties égales $(p / v)$ dans le «tampon de WEYBRIDGE », Le récipient est alors placé à $+4^{\circ} \mathrm{C}$.

\section{Antigène typhose aviaire.}

La culture de Solmonella gollinarum 9 R-S R est faite en boîte de Roux sur gélose dont la composition est la suivante : 
Lactate de soude. $3,5 \mathrm{ml}$

Phosphate monosodique......... $3 \mathrm{gr}$

Tryptone ................... $15 \mathrm{gr}$

Yeast Extract Difco........... 2,5 gr

Glucose ................. 2 gr

Chlorure de sodium ......... $5 \mathrm{gr}$

Gélose ................... $20 \mathrm{gr}$

Equ distıllée .............. $1.000 \mathrm{ml}$

Les boîtes sont ensemencées avec un inoculum préparé la vellle en bouilion tryptose à partir d'un isolement réalisé sur une gélose-sérum ensemencée avec un flacon rehydraté de la banque lyophilısée.

Les boîtes sont laissées 48 heures à l'étuve à $37^{\circ}$ puis chacune d'elles est vérifiée quant à la pureté de la culture.

Cinquante millilitres de «tampon de WEYBRIDGE » $\left({ }^{*}\right)$, ainsi que des billes de verre sont introduits dans chaque boîte. La couche de Salmonelles est décollée par simple va-eł-vient des billes de verre et du liquide sur la gélose. Le contenu de chaque boîte de Roux est alors filtré sur gaze et recueilli dans un ballon de 10 litres qui est conservé au froid.

\section{Confection du vaccin - Lyophilisation.}

II va sans dire que le vaccin résultant du mélange des trois antıgènes différents sera d'autant meilleur que ces antigènes n'auront subi aucune congélation-décongélation avant leur mélange, ce qui revient à dire qu'il est indispensable que les récoltes de ces trois antigènes soient effectuées en même temps. Ełant donné les différentes modalités de culture et les temps de récolte variables, il convient de respecter scrupuleusement un plan déterminé à l'avance.

Voici dans l'ordre chronologique quel doit être le déroulement des différentes opérations.

Jour J - Mise en culture de cellules de rein d'embryon de veau en boîte de Roux.

(*) Le «tampon de Weybridge » esł un diluant utılisé dans ce laboratoire pour la lyophilisation de Brucella abortus B 19 (5), de composition suivante :

\footnotetext{
Hydrolysat de caséine.......... 25

Saccharose ................ 50

Glutamate de sodium.............. 10

Eau distillée............ Q. S. $1.000-\mathrm{pH}: 7,2$ Stérilisation de 30 minutes à $110^{\circ} \mathrm{C}$.
}

Jour $\mathrm{J}+5$ et $\mathrm{J}+7$ - Repiquage en flacons tournant des cultures cellulaires réalisées en boîte de Roux.

Jour J + 10 - Inoculation des cellules de seconde explantation de $\mathrm{J}+5$ avec la banque de virus de la variole aviaire, souche BEAUDETTE.

Jour J +12 - Isolement sur gélose sérum de Salmonella gallinarum souche 9 R-S R à partir de la banque lyophilısée.

Jour J +13--. Infection des cellules de deuxième explantation de $\mathrm{J}+7$ avec la banque de virus de la Maladie de Newcastle souche BANKOWSKI.

- Ensemencement avec l'isolement de S. gollinarum 9 R-S R d'un ballon de bouillon devant servir d'inoculum pour les boîtes de gélose ; identification biochimique de la culture.

Jour J + 14 - Infection des boîtes de gélose avec l'inoculum préparé la veille.

Jour J +16-Récolte des différents antigènes et confection du vaccin polyvalent définitif.

Pour les cas où l'antigène variolique est produit en ovoculture, des œufs sont mis à incuber le jour $J$ et sont inoculés comme il a été dit le jour $\mathrm{J}+10$.

Toutes ces opérations doivent être accomplies avec le plus grand soin, en s'entourant du maximum de garanties car le moindre retard apporté à la réalisation de l'une d'entre elles peut compromettre définitivement la confection du vaccin polyvalent.

Les proportions du mélange terminal sont les sulvantes :

- une partie : milieu de culture et cellules broyées infectées avec la souche BANKOWSKI, - une partie : milieu de culture et cellules broyées infectées avec la souche BEAUDETTE de variole aviaire ou récolte de membranes chorioallantoldiennes broyées en tampon de WEYBRIDGE,

-8 parties : suspension de S. gallinarum 9 R-S R d'opacité égale au moıns au tube no 7 de I'échelle opacimétrique de BROWN, c'est-à-dire environ 5 millıards de germes par ml. Pour ce faire, la récolte de salmonelles est diluée extemporanément dans la quantité requise de tampon de WEYBRIDGE glacé. 
Le mélange des différents constituants est réalisé sous froid et dans les meilleures conditions d'asepsie.

Pour abtenir 8 litres de vaccin polyvalent, il est nécessaire d'infecter une vingtaine de flacons de cellules en culture (ou 10 flacons de celiules ef 300 œufs lorsque l'antigène variolique est produit en ovoculture) et d'ensemencer 80 boîtes de gélose (Boîtes de Roux de 1 litre).

Les antibiotiques contenus dans le milieu de croissance des cellules en culture sont suffisants pour empêcher les contaminations bactériennes toujours possibles du vaccin lors des manipulations ; il n'en est pas rajouté.

Le vaccin est réparti toujours sous froid dans des flacons de $17 \mathrm{ml}$ sous un volume de $3 \mathrm{ml}$, puis il est soumis à une lyophilisation lente durant 48 heures.

Pour ce faire, après congélation des flacons dans l'appareil (*), on établit le vide tout en mainfenant pendant 24 heures la température à $-30^{\circ} \mathrm{C}$, les 6 heures suivantes on réchauffe progressivement à la température ambiante ef on continue à sublimer à cette température pendant18 heures.

Après bouchage sous vide et capsulage, le vaccin est stocké dans des congélateurs à $-20^{\circ} \mathrm{C}$.

Chaque flacon contient 50 doses de vaccin. Son nom de code est Polavia.

\section{Contrôles de laboratoire.}

\section{A. - Contrôles de survie des germes.}

Avant le mélange final qui doit constituer le vaccin polyvalent, quelques millilitres de chaque constituant sont prélevés. Chacun de ces prélèvements est mélangé à une certaıne quantité de tampon de WEYBRIDGE de façon à obtenır pour chacun la dilution qu'il possède dans le mélange terminal. Ces différents prélèvements aınsı dilués, véritables vaccins monovalents, sont répartis et lyophilisés de la même façon que le vaccin définitif. C'est sur eux que se feront les contrôles de survie des germes et, pour les deux antigènes viraux, ceux de pureté bactérıologique.

a) Pour le constituant Maladie de Newcastle le titrage sera réalisé sur œufs embryonnés de 10 jours. Le contenu d'un flacon lyophılisé

(*) Stokes Co, Philadelphia, Pa, U. S. A. correspondant au constituant BANKOWSKI du POLAVIA est repris dans 50 millilitres d'eau distillée puis, à partir d'un millılitre, des dilutions en progression géométrique de raison 10 sont effectuées en eau distillée. Cinq œufs sont inoculés dans l'allantoide avec chacune de ces dilutions. Les inoculations se font jusqu'à la dilution $10^{-6}$. Trente œufs embryonnés de 10 jours sont done nécessaires pour ce titrage.

Vingt-quatre heures après l'inoculation, les cufs sont mirés ef les morts éliminés. Les jours suivants les œufs morts sont ouverts ef la présence du virus de Newcastle recherchée dans le liquide allantoïdien par hémagglutination sur lame de globules rouges de poulet. Le titre est exprimé en dose infectieuse 50 p. 100 pour l'cuf embryonné (DIE ${ }_{50}$ ) ; BANKOWSKI, CORSTVET ef FABRICANT ont montré (3) que la dose vaccinale était de $10^{4,3} \mathrm{DIE}_{60}$ si l'on voulait obtenir une forte immunité anti-Newcastle. C'est la norme minimale que doivent montrer les contrôles, norme aisément dépassée dans la pratique lorsque sont respectées les conditions de préparation du vaccin.

b) Le titrage du constituant variole est également effectué sur œufs embryonnés de 10 jours mais en partant d'un flacon lyophilisé correspondant au constituant variole aviaire et en inoculant les cufs selon la méthode de JOHNSON ef VAUGHAN (18) por le bout pointu de l'œuf. Les inoculations sont faites jusqu'à la dilution 10-6. Vingt-quatre heures après l'inoculation, les œufs sont mirés et les morts éliminés. Après le troisième jour les cufs contenant des embryons morts sont auverts et les membranes examinées. Le sixième jour tous les œufs restants sont ouverts. Toutes les membranes chorio-allantoïdiennes ayant présenté après le trolsième jour un cedème caractéristique ovec pustules sont comptabilisées.

Ces lésions étant la preuve de la présence du virus variole dans les oufs, le titre en dose infectante œuf 50 p. $100 \mathrm{DIE}_{50}$ est calculé selon la méthode des totaux cumulatifs.

Pour que le composant variole aviaire solt valable le titre doit être d'au moins $10^{4} \mathrm{DIE}_{50}$ par dose vaccinale poulet.

c) Le titrage du constituant typhose est effectué selon la méthode statıstıque classique de la numération bactérienne en tube (11). Ce 
titrage ne falt que confirmer l'évaluation du nombre de germes réalisés à l'échelle de BROWN lors de la récolte des salmonelles. Nous avons vu que la suspension de salmonelles en tampon de WEYBRIDGE doit avoir un titre au moment $d u$ mélange final d'au moins 5 milliards de germes au millilitre. Les vaccins réalisés à Farcha présentent des titres se situant entre 7 et 9 milliards de germes au millilitre de récolte ce qui, tenant compte d'environ 50 p. 100 de pertes lors de la. lyophilisation donne 100 millions de germes viables par dose vaccinale.

\section{B. - Contrôles de pureté.}

Ils visent non pas précisément à mettre en évidence la stérilité bactériologique des composants viraux du vaccin et l'absence de souillures du composant typhose plutôt que l'absence d'organismes pathogènes. Il est en effet difficile après passage dans l'appareil à lyophiliser d'avoir des produits totalement exempts de germes banals de contamination.

Les contrôles sont effectués sur les produits monovalents. Chacun d'eux est ensemencé en bovillon ordinaire, en bovillon VF anaérobie, sur gélose SABOURAUD, en bouillon spécial pour la recherche des mycoplasmes. Après 3 et 8 jours d'étuve, des contrôles de croissance sont effectués et le cas échéant des identifications menées à bien.

Pour les lots de vaccins où le composant variole a été prodult en ovoculture, il eût été nécessaire d'adjoindre un contrôle d'absence du virus RIF, soit par la méthode d'interférence (24) soit par le test COFAL. II s'agit là de techniques qu'il ne nous est pas possible de mettre ordinairement en œuvre. Toutefois, étant donné la source des œufs utilisés (élevage français très soigneusement contrôlé et apparemment indemne de leucose viscérale), if y a peu de chances que des virus leucosiques aient été présents dans le vaccin. On se rappellera par ailleurs que ces lots étaient destinés à vacciner des volailles d'importation, elles-mêmes non assurément indemnes de leucose.

\section{Contrôles d'efficocité.}

Pour chaque lot de vaccin dix poulets de race locale âgés de deux à trols mois sont utilisés. Six d'entre eux reçoivent une dose de vaccin par injection intramusculaire dans les muscles pectoraux. Les quatre autres servent de témoins. Trois poulets vaccinés serviront au contrôle du composant Newcastle, trois à celui de la variole aviaire.

\section{- Maladie de Newcastle.}

Une prise de sang (2 mililitres) est faite sur chacun des poulets avant la vaccination. Une réaction d'inhibition de l'hémagglutination selon la méthode de HIRST (procédé bêta : virus constont-sérum dilué) (1) est réalisée sur chaque sérum afin de mettre en évidence l'absence d'anticorps inhibant l'hémagglutination.

Trois semaines plus tard une nouvelle prise de sang est effectuée sur les poulets et une nouvelle réaction d'inhibition de l'hémagglutination est effectuée sur chaque sérum. Le sérum des animaux vaccinés doit inhiber jusqu'à la dilution 1 : 20 dix unités hémagglutinantes pour que l'immunité acquise par les poulets vaccinés soit considérée comme convenable. On remarquera au passage, ce qui est connu, que la souche BANKOWSKI eșt une faible génératrice d'anticorps inhibant I'hémagglutination.

Cette immunité sera en plus vérifiée par une épreuve virulente réal isée 40 jours après la vaccination avec la souche pathogène P. $63\left(^{*}\right)$. Trois oiseaux vaccinés résisteront à l'inoculation intramusculaire de 0,5 millilitre de liquide allantoïque d'œufs infectés par la souche P. 63 alors que deux témoins inoculés mourront dans un délaj de 8 jours.

- Variole avicire.

Trois poulets vacanés et deux témoins sont éprouvés 40 jours après la vaccination avec une souche pathogène locale de variole aviaire par scarification sur la crête. Chez les vaccinés apparaissent en 48 heures sur les stries de scarification des croûtes sèches qui tombent en quelques jours; il n'y a aucune généralisation dans la bouche et les sinus. On est en présence des réactions d'allergie vaccinale communes à toutes les varioles (15). Chez les témoins par contre, après un épisode congestif des traits de scarification, les vésicules et les pustules n'apparaissenf que 6 à 8 jours après l'inoculation. Ces lésions

(*) Souche française originaire de l'Institut Pasteur de Paris. 
épithéliomateuses sont nombreuses et souvent deviennent confluentes autour de l'œil. II n'a jamais été obtenu cependant de généralisation à la bouche et aux sinus sur les oiseaux que nous avons éprouvés.

\section{- Typhose aviaire.}

La valeur de l'immunıté conférée par la vaccination à l'égard de la typhose devrait être confirmée par une épreuve virulente comparable aux épreuves imposées à l'encontre de l'immunité anti-Maladie de Newcastle et de l'immunité antivariolique.

Dans ce but, plusieurs tentatives ont été effectuées qui se sont toutes soldées par des échecs. En effet il n'a jamais été possible de transmettre, de quelque manière que ce soit, la typhose aux témoins non vaccinés. De ce fait, la valeur de l'immunité vis-à-vis de cette affection n'a jamais pu être prouvée au laboratoire, vaccinés et témoins se comportent après l'épreuve virulente de la même façon sans montrer aucun symptôme de maladie.

Devant cet état de fait il est logique de penser que la protection réelle et reconnue conférée aux poulets «sur le terrain » vis-à-vis de Salmonella gallinarum doive être attribuée au nombre très élevé de germes contenus dans chaque dose vaccinale. Réciproquement, il est normal de conclure qu'un vaccin qui répond aux normes établies quant au nombre des germes contenus par dose vaccinale procure une immunité effective contre la typhose même si cette immunité ne peut être démontrée au laboratoire par l'inoculation d'une souche pathogène.

\section{III. - UTILISATION DU VACCIN POLYVALENT}

\section{Innocuité - Age de la vaccination.}

Lors de la conception de ce vaccin, on pouvait redouter que l'association des 3 antigènes ne se montrât pathogène. Il était déjà reconnu que chacun d'eux pris séparément était d'une innocuité parfaite pour le poussın d'un jour $(3,18,28)$ mais on ne savait rien des effets du mélange.

Dans ce but, 50 poussıns de race locale âgés de quelques jours et 50 poussins LEGHORN âgés de 1 jour sont inoculés par voie intramusculaire avec $1 \mathrm{ml}$ de vaccin reconstitué (contenu d'un flacon repris dans $50 \mathrm{ml}$ d'eau). Aucun trouble morbide ni apparemment aucun retard de croissance chez les LEGHORN comparés d 50 poussins témoins n'est noté en 6 mols d'observation.

Par simple mesure de sécurité, et pour tenir compte de la disparition d'une immunité parentale pouvant interférer avec l'ımmunisation, l'âge préconisé pour la vaccination a été porté à 3 semaines. L'expérience de 25.000 poussins environ, vaccinés dans ces conditions et suivis jusqu'à l'âge de 2 mois, montre le bien fondé de cette recommandation.

Un utilisateur de Bangur a signalé avoir jusqu'à 4 p. 100 de pertes dues à des paralysies chez les poussins vaccinés à l'âge de 5 à 6 semalnes. C'est effectivement un fait qui a été constaté au laboratoire sur des poussins LEGHORN élevés dès leur naissance en poulaillers comme l'étaient ceux de Bangui ; on a pu observer 2 poussins. montrant des troubles nerveux (incoordination motrice) 3 jours après l'intervention et mourant paralysés 2 jours plus tard. A l'autopsie, on notait de nombreuses pelotes de ténias dont l'action sur le système, nerveux des oiseaux est connue. Dans les conditions d'élevage de l'Afrique centrale et tenant compte des cycles parasitaires, on s'aperçoit que l'âge de 6 semaines est la période où les jeunes poulets peuxent héberger le maximum d'helminthes (Railletina, Choanotoenia. Hymenolepis mais aussi Ascoridia), quand ce ne sont pas des coccidies; ce fait explique en partie la genèse des accidents. II est toutefois indéniable que le composant Bankowski du vaccin possède un indice de neuro-virulence plus élevé que les souches lentogènes (Hitchner BI, La Sota) et qu'il puisse être lui aussi responsable d'accidents nerveux.

Une ample pratique montre que la vaccination à 3 semaines est parfaitement tolérée. C'est l'âge que nous recommandons plutôt que celui de 5 à 7 semaines dans les conditions des élevages avicoles familiaux et améliorés d'Afrique centrale.

Chez les olseaux âgés de plusieurs mois, voire chez les adultes, la vaccination est parfaitement supportée, pour autant qu'ils ne soient pas en état sanitare insiable. Sur les poulets de race locale vaccınés sans discrimınation, parasités massivement par les helminthes déjà cités ou infectés latents de typhose, il est en certaines circonstances possible d'observer une certaine mor- 
talité post-vaccinale. C'est pourquoi nous nous permettons d'ınsister sur l'âge de 3 semaınes déjà recommandé pour la vaccination, pratique qui de surcroît conduit, on le verra plus loın, àune immunité de longue durée.

II paraît superflu d'ajouter car il a déjà été insisté sur ce point, que la vaccination doit s'effectuer par voie intramusculaire, la dose étant de $1 \mathrm{~m}$ l de vaccin reconstitué obtenu après reprise de la pastille lyophilisée dans $50 \mathrm{ml}$ d'eau distillée. Pour l'inoculation, on choisira une aiguille courte et fine ; le duvet sera écarté en soufflant dessus et l'aiguille sera enfoncée là où la peau est glabre.

\section{Pouvoir immunigène - Durée de l'immunité.}

Cette recherche a été conduite au laboratoire pour les composants Newcastle et variole; les résultats enregistrés ant été largement confirmés dans la pratıque. Ainsi qu'il a été dit au moment des contrôles, en ce qui concerne le composant typhose, on a dô se contenter des résultats enregistrés sur le terrain.

- Maladie de Newcastle. L'expérience a été réalisée d̀ deux reprises avec des résultats identiques. Cinquante volailles (poules et cogs) de race LEGHORN blanche reçoivent à l'âge de 3 semaines $1 \mathrm{ml}$ de vaccin par voie intramusculaire.

Aux âges de 2 mois, 6 mois, 12 mois et 18 mois (la plus longue période expérimentée), 6 oiseaux reçoivent par les voies nasales, oculaires et trachéales le virus de Newcastle souche pathogène $P 63$ (liquide allantolque d'œuf infecté dilué au 1/100) en même temps qu'à chaque fois deux témoịns non vaccınés nés de la même éclosıon et entretenus avec les vaccinés. Ces derniers font dans les huit jours une maladie de Newcastle à prédomınance symptomatologique nerveuse et meurent; la santé des vaccinés reste bonne; les poules en ponte ont continué à pondre. Un Incident néanmains est digne d'être rapporté : les coqs vaccinés puis éprouvés 18 mols après la vaccination ont été remis deux mois après l'épreuve virulente au contact de poules non vaccinées; une dizaine de jours plus tard, la maladie de Newcastle décimalt ces dernières, laissant les coqs introduits en parfaite condition ; i) est tentant en ces circonstances d'accuser ces derniers d'avoir introduit le contage.

II ressort néanmoins de ces contrôles qu'une immunité d'au moins 18 mois suit la vaccination au POLAVIA.

- Variole aviaire. Les mêmes oiseaux vaccinés, déjà éprouvés contre la maladie de $\mathrm{New}$ castle, sont éprouvés les $3 \mathrm{e}, 7 \mathrm{e}, 13^{\mathrm{e}}$ ef $19 \mathrm{e}$ mois avec une souche pathogène locale de variole aviaire par scarification de la crête, en même temps qu'à chaque fois 2 témoins non vaccinés n'appartenant pas forcément à la même éclosion. Ces derniers réagissent classiquement en 6 à 10 jours par un épithelioma contagieux alors que les vaccinés présentent une évolution abortive en 2 a 3 jours sauf un sur six des coqs éprouvés le $19 \mathrm{e}$ mois.

If apparaîf donc que l'on puisse compter sur une excellente immunité d'au moins un an, 18 mois même pour certains oiseaux. Il paraît important de faire remarquer que les oiseaux vaccınés présentaient tous avant les épreuves virulentes de nombreuses petites croûtelles noirâtres sur la crête et les barbıllons, cicatrices vraisemblablement témoıns de réinfections locales varioliques par piqûres de moustiques infectés. Il s'agit d'ailleurs là d'une observation extrêmement commune sur nombre de poules d'Afrique centrale. Non seulement on se gardera de prendre ces croôtelles pour d'authentıques lésions varioliques, mais bien plus elles doivent avoir I'heureux effet de vaccinations de rappel. A tout prendre, l'immunité antivariolique engendrée par le POLAVIA doit durer la vie économique des volailles. C'est ce que l'on constate dans un élevage du laboratoire et dans des parquets de pondeuses près de Fort-Lamy où depuis l'introduction du vaccin polyvalent la variole est cliniquement Ignorée sur les oiseaux vaccinés.

\section{Utilisation sur le terrain.}

Introduit au Tchad en novembre 1963, le vaccin aviaire polyvalent jouit maintenant d'une estime certane en Afrique centrale et même accidentale (Niger, Côte-d'Ivoire). II n'est qu'un éleveur de la République du Congo ef une statıon avicole camerounaise qui préfèrent faire appel à d'autres vaccins.

Le tableau 1 montre qu'il tend à supplanter les autres vaccins avaaires produits par le laboratoire de Farcha. Si deux d'entre eux (HITCHNER et vaccin inactivé) restent utilisés dans certains élevages, c'est en raison de problèmes spécifiquement locaux. 
TABLEAU $\mathrm{N}^{\circ} \mathrm{I}$

Evolution des demandes en vaccins aviaires pour les territoires

d'Afrlque centrale de 1957 à 1968

\begin{tabular}{|c|c|c|c|c|}
\hline Année & Vaccins Newcastle & Vaccins Variole & Vaccins Typhose & Vaccins Polyvalerts \\
\hline 1957 & 2.000 & 840 & 1.500 & \\
1958 & 200 & 1.500 & 26.400 & \\
1959 & 95.000 & 75.000 & 8.650 & \\
1960 & 44.850 & 13.450 & 16.900 & \\
1961 & 49.000 & 26.000 & 21.370 & \\
1962 & 29.450 & 14.970 & 28.020 & 41.900 \\
1963 & 24.100 & 8.400 & 24.200 & 46.700 \\
1964 & 79.600 & 20.700 & 12.000 & 197.100 \\
1965 & $84.905()$. & 9.605 & 3.000 & 219.650 \\
1966 & $28.000(.)$. & 1.700 & 0 & 174.000 \\
1967 & $81.000(.)$. & 2.400 & & \\
\hline
\end{tabular}

(.) dont 52.800 doses de vaccin inactivë et de vaccin souche Hitchner $B_{1}$.

(..) 28.000 doses de vaccin Inactivé.

(...) 17.000 doses de vaccin inactivé et 51.000 doses de vaccin souche Hitchner $B_{1}$ et 13.000 doses de vaccln souche Komarov.

Il est difficile de donner une impression d'ensemble sur l'efficacité de la vaccination. Les utılisateurs s'accordent pour dire qu'employé en milieu sain le POLAVIA protège contre les 3 maladies pour lesquelles il est préconisé ; cela doit être vrai, pensons-nous, pour la variole et la typhose dont on est sûr qu'elles existent. En milieu infecté de typhose, l'efficacité esł moins nette. Cette réflexion montre tout l'intérêt de la vaccination dès le jeune âge, pour autant que les poussins proviennent d'accouveurs indemnes d'infection typho-pullorique.

Une très récente incursion de maladie de Newcastle dans la région lamyfortaine vient encore de montrer le bien fondé des propositions émises. Sur les 6.000 volailles environ de races améliorées vaccinées qui s'y trouvent, la protection a été parfaite pour plus de 4.000 . Sur le reste, on a observé une immunité partielle avec environ 5 p. 100 de mortalité, des râles respiratoires ef une chute temporaire de ponte; les autopsies pratiquées indiquaient que ces oiseaux partıellement immuns étaient soit massivement parasités par des ténias, soit porteurs d'infection ovarienne typho-pullorique. Les coupes histologiques de trachées ont montré une réaction proliférative de défense de la muqueuse et non de nécrose comme chez les poulets non immu- nisés. Sur une bande de 250 poulets de 4 mois vaccinés à deux reprises (à 3 semaines et à 3 mois), la mortalité due à la maladie de Newcastle a été lourde; l'anamnèse indiquait que ces oiseaux avaient connu un épisode d'érythroblastose dans leur jeune âge, si bien qu'un doute puissant peut être émis quant à l'intégrité de leur système immuno-formateur. Il est à signaler enfin qu'un élevage non vacciné a perdu la totalité de ses sujets et que les volailles locales, non vaccinées ont presque totalement disparu des environs de Fort-Lamy. Au moment où ces lıgnes sont écrites, l'épızootie gagne rapıdement vers le Sud du Tchad, affirmant l'opinion émise dans l'introduction.

Dans sa forme actuelle, le vaccin avıaire polyvalent est relativement satisfaisant.'A notre sens, il dolt être perfectible. Dans un premier temps, on pourrait éventuellement remplacer la souche BANKOWSKI par une autre souche cultivable sur cellules hétérologues mals à neurovirulence moindre si cette dernière détermıne une immunité d'aussı longue durée que la souche BANKOWSKI. L'autre perfectionnement à apporter sera l'adjonction d'un Immunigène spirochétose actuellement à l'étude. Ainsi ce vaccin apportera-t-il vraiment une aide encore plus efficace au développement de l'aviculture en Afrique centrale. 


\section{BIBLIOGRAPHIE}

1. Anonyme. - Methods for the examination of poultry biologics. Publication 1038. National Academy of Sciences, National Research Council. Washington D. C. 1963.

2. BANKOWSKI (R. A.). - A tissue culturemodified Newcastle disease virus. I. Modification, preparation and characteristics of the tissue culture Newcastle disease virus Avion Dis., 1958, 2, 197-209.

3. BANKOWSKI (R. A.), CORSTVET (R.) et FABRICANT (J.). - A Tissue culture-modified Newcastle disease virus. II. Immunogenicity of the live tissue culture-modified Newcastle disease virus in chickens. Avion Dis., 1958, 2, 227-240.

4. BASSET (J.). - Quelques maladies infectieuses. Paris, Vigot Frères, 1946.

5. BOYCE $(K$, J.) ef EDGAR $(A . W$.$) . - Pro-$ duction of freeze-dried Brucella aborfus strain 19 vaccine. J. appl. Bact., 1966, 29, 401408.

6. BREMAUD (O.). - République du Tchad; Rapport annuel 1964 de la Direction de I'Elevage. Fascicule VIII, p. 8/66.

7. BRION (A.) et FONTAINE (M.). - Progrès récents dans la connaissance de l'étiologie des leucoses aviaires. Econ. Méd. Anim., 1964, 5, 223-237.

8. BURMESTER (B. R.), CUNNINGHAM (C. H.), COTTRAL (G. E.), BELDING (R. C.) ef GENTRY (R. F.) - - The transmission of visceral lymphomatosis yirus with live Newcastle disease vaccines, Am. J. Vet, Res., 1956, 17, 283-289.

9. DEPOUX (R.) et CHAMBRON (J.). - Note préliminaire sur l'incidence de la pseudopeste aviaire dans la République du Congo. Rev. Elev. Méd. vét. Pays trop., 1960, 13, 53-56.

10. DUNLOP (W. R.), KOTTARIDIS (S. D.), GALLACHER (J. R.), SMITH (S. C.) et STROUT (R. G.). - - The defection of acute avian leucosis as a contagious disease. Poultry Sci., 1965, 44, 1537-1540.

11. FISHER (R. A.) et YATES (F.). - Statistical tables for biological, agricultural and medical research. London, Oliver and Boyd, 1953, p. 57.
12. GORDON (R. F.), GARSIDE (J. S.) et TUCKER (J.F.). - The use of living attenuated vaccines in the control of fowl typhoid. Vet. Rec., 1959, 71, 300-305.

13. GRABER (M.). - Rapport annuel du Laboratoire de Recherches vétérinaires de Farcha, année 1966.

14. HARBOURNE (J. F.). - The control of fowl typhoid in the field by the use of live vaccines. Vet. Rec., 1957, 69, 1102-1107.

15. JOUBERT (L.) et VALETTE (L.). — Les virus vaccino-varioliques des animaux. Quelques aspects de virologie comparée. Symposium international sur la vaccination antivariolique, Lyon 7-8-9 décembre 1962. Lyon, Edition Institut Mérieux, 1963, p. 83-106.

16. KARRAR (G.) et MUSTAFA (E.). - Newcastle disease in the Sudan. Bull. O. I. E., $1964,62,891-896$.

17. KASCHULA (V.R.). - A comparison of the specirum of disease in village and in modern poultry flocks in Nigeria. Bull. epiz. Dis. Afr., 1961, 9, 397-407.

18. JOHNSON (R. H.) et VAUGHAN (R.). Production and use of fowl pox vaccine in Nigeria. Bull. epiz. Dis. Afr., 1962, 10, 441450.

19. MALBRANT (R.). - Pseudo-peste aviaire au Moyen-Congo. Rev. sci. Méd. Pharm. Vét. France libre, 1942, 1, 239-240.

20. MORGAN (H. R.). - Antibodies for Rous sarcoma virus in fowl, animal and human populations in East Africa. 1. Antibodies in domestic chickens and wildfowl. J. Nat. Cancer Inst., 1965, 35, 1043-1045.

21. PERPEZAT (A.), PERREAU (P.), THOME (M.) et VIGIER (M.). - Différents sérotypes de salmonelles isolées en République du Tchad. Rev. Elev. Méd. vét. Pays trop., 1964, 17, 35-41.

22. PIERCY (S, E.), - The immunising properties of an egg-adapted strain of fowl pox virus. J. comp. Path., 1952, 62, 152.

23. PROVOST (A.), VALETTE (L.) et PAPAGEORGIOU (C.). - Un vaccin injectable contre la maladie de Newcastle préparé en cultures de cellules bovines. Bull. Acad. Vét. $F r ., 1962,35,399-402$. 
24. THOME (M.). - Rapports annuels du Laboratoire de Recherches vétérinaires de Farcha, années 1963, p. 115-119 et 1964, p. 115117 et 272-275.

25. VANDEMAELE (F, P.). - The epizootiology of Newcastle disease in Africa south of the Sahara. Bull. epiz. Dis. Afr., 1961, 9, 371-381.

26. VERVUST (H.) et GRAVE (N.). - La maladie des barbillons, forme chronique du choléra des poules dans la région de Lubero. I. Etude clinique. Bull. agric. Congo belge, 1959, 50, 1053-1062.

27. VIGIER (M.) et CHAMOISEAU (G.). - Rôle possible d'animaux à sang froid dans l'in- fection de l'homme et de l'animal domestique par quelques Entérobactéries. Rev. Elev. Méd. vét. Pays trop., 1967, 20 (ce numéro).

28. WILLIAMS SMITH (H.). - The use of live vaccines in experimental Salmonella gallinarum infection in chickens with observations on their interference effect. J. Hyg., 1956, 54, 419-432.

29. WITTER (R. L.), CALNEK (B. W.) et LEVINE (P. P.). - Occurence of lymphomatosis in chickens free of resistance-inducing factor (RIF) virus. Avion Dis., 1966, 10, $32-42$. 